\title{
A Comparative Study to Assess the Competency among Nurses in Giving Neonatal Skin Care in Selected Government and Private Hospitals in Delhi and to Disseminate TNAI Guidelines 2017 on Neonatal Skin Care
}

\author{
$\underline{\text { Shweta', } \text { Bindu Shaiju }^{2}, \text { Anjali Kaushik }^{3}}$ \\ ${ }^{1}$ M.Sc. Nursing $2^{\text {nd }}$ Year, ${ }^{2}$ Assistant Professor, ${ }^{3}$ Tutor, Rufaida College of Nursing, Jamia Hamdard, New Delhi. \\ DOI: https://doi.org/10.24321/2455.9318.201822
}

\begin{abstract}
Neonatal skin care is an important clinical concern for nurses who care for newborns, including well, fullterm, healthy premature and extremely premature neonates. Skin performs a vital role in the newborn period. It provides a protective barrier that assists in the prevention of infection, facilitates thermoregulation and helps control insensible water loss and electrolyte balance. Other functions include tactile sensation and protection against toxins. Routine care practices including bathing, application of monitoring devices, intravenous (IV) catheter insertion and removal, tape application, and exposure to potentially toxic substances disrupt the normal barrier function and predispose both premature and term newborn to skin injury. The skin of the full-term newborn is coated with vernix caseosa, a cheese-like substance that contains sebum from sebaceous glands, broken-off lanugo and desquamated cells from amnion, as well as water. Skin care practices play an important role in the health of well newborns and hospitalized neonates. Fortunately, for many aspects of neonatal skin care, there exit evidence or consensus-based recommendations to guide best practices.

Keywords: Neonatal skin assessment, Neonatal skin care, Eye care, Umbilical cord care, Diaper care, Guidelines
\end{abstract}

\section{Introduction}

The most important function of the skin is to protect against water loss, absorption of noxious substances, intrusion of microorganisms, and physical trauma. The skin of infants is morphologically and functionally different from the skin of adults. Within their first days of life, babies undergo various adaptation processes needed to accommodate the transition from the wet uterine environment to the dry atmosphere. During the first months and even years (depending on the parameter), the skin continues to develop and evolve its structure and functions. ${ }^{1}$

The skin of the full-term newborn is coated with vernix caseosa, a cheese-like substance that contains sebum from sebaceous glands, broken-off lanugo and desquamated cells from amnion, as well as water. Vernix begins to form as early as $17-20$ weeks of gestation, with the thickest coating noted between 36 and 38 weeks. By 40 weeks, it is found primarily in skin creases. Vernix protects the

Corresponding Author: Ms. Shweta, Rufaida College of Nursing, Jamia Hamdard, New Delhi.

E-mail Id: shweta.gahalian15@gmail.com

Orcid Id: https://orcid.org/0000-0002-8269-8697

How to cite this article: Shweta, Shaiju B, Kaushik A. A Comparative Study to Assess the Competency among Nurses in Giving Neonatal Skin Care in Selected Government and Private Hospitals in Delhi and to Disseminate TNAI Guidelines 2017 on Neonatal Skin Care. Int J Nurs Midwif Res 2018; 5(2): 47-50. 
fetus from maceration from amniotic fluid and allows the fetus to move without chafing as it grows in utero. Vernix caseosa assists in the development of the "acid mantle" of the skin surface, which inhibits the growth of pathogenic microorganisms and imparts immunologic properties to the skin. ${ }^{1}$

The skin surface $\mathrm{pH}$ in premature infants of varying gestational ages has been reported to be more than 6 on the first day of life, decreasing to 5.5 by the end of the first week, and then to 5.1 by the end of the first month of life. ${ }^{2}$

Skin care practices play an important role in the health of well newborns and hospitalized neonates. Fortunately, for many aspects of neonatal skin care, there exists evidence or consensus-based recommendations to guide best practices. $^{3}$

The skin of a premature infant can comprise up to $13 \%$ of its body weight, compared with $3 \%$ in adults. This large organ serves as a barrier to infection, protects internal organs, contributes to temperature regulation by preventing evaporative heat loss and insensible water loss, stores fat, and provides tactile sensory input. The sensations of touch, pressure, temperature, and pain are received by millions of microscopic nerve endings in the skin. ${ }^{4}$

Skin is instrumental in the initial establishment of the mother-infant relationship. Skin-to-skin contact, beginning immediately after delivery for the healthy newborn, is an important sensory experience for both the mother and the infant. When the newborn needs intensive care this may not occur initially, but hopefully can be initiated in the newborn intensive care unit (NICU). ${ }^{4}$

\section{Objectives of the Study}

The study aimed to assess the competency among nurses in giving neonatal skin care in selected government and private hospitals in Delhi and to compare the competency among nurses in giving neonatal skin care in a selected government and a private hospital in Delhi. The objectives also included dissemination of TNAI guidelines 2017 on neonatal skin care to the nurses.

\section{Materials and Methods}

A comparative survey design was selected for the study. The setting of the study was Saroj Super Specialty Hospital, Delhi, which is a private setting and Baba Saheb Ambedkar Hospital, Delhi, which is a government hospital. In the present study, the sample comprised 60 nurses of the government and private hospital, working in PNC ward, labor room and NICU. Convenient sampling technique was adopted to select the samples. After obtaining ethical permission from the Institutional Ethical Committee of Jamia Hamdard, New Delhi, to conduct the research study, a formal permission for conducting research was obtained from the selected hospital of Delhi. A written informed consent was taken from each study subject. They were assured of anonymity and confidentiality of the information provided during the research study. The final study was conducted in Saroj Super Specialty Hospital, Delhi, which is a private setting and Baba Saheb Ambedkar Hospital, Delhi, which is a government hospital. The subjects comprised nurses of the government and private hospital, working in PNC ward, labor room and NICU. Data was collected using a structured tool and prepared checklist from TNAI 2017 manual to assess the competency among nurses in giving neonatal skin care in the selected government and a private hospital in Delhi. Descriptive and inferential statistics were used for data analysis.

\section{Results}

\section{Sample Characteristics}

According to age group, in the government hospital, 50\% $(n=15)$ of nurses were of age group of $20-35$ years and $50 \%$ $(n=15)$ of nurses were in the age group of $35-50$ years, whereas in the private hospital, majority $93.3 \%(n=28)$ of nurses were in the age group of 20-35 years and 3.3\% $(n=1)$ of nurses were in the age group of $35-50$ years and 50-60 years.

According to gender, in the government hospital, $80 \%$ $(n=24)$ of nurses were females and $20 \%(n=6)$ nurses were males, whereas in the private hospital, $83.3 \%(n=25)$ of nurses were females and $16.7 \%(n=5)$ nurses were males.

According to experience, in the government hospital $53.3 \%(n=16)$ of nurses were having more than 10 years of experience, $40 \%(n=12)$ of nurses were having experience of $5-10$ years and $6.7 \%(n=2)$ of nurses were having $1-5$ years of experience, whereas in the private hospital, $6.7 \%(n=2)$ of nurses were having more than 10 years of experience, $20 \%(n=6)$ of nurses were having experience of $5-10$ years and $53.3 \%(n=16)$ of nurses were having $1-5$ years of experience and $20 \%(n=6)$ of nurses had less than 1 year of experience.

According to qualification, in the government hospital, most $76.7 \%(n=23)$ of the nurses had done DGNM, followed by $3.3 \%(n=1)$ of nurses had done Post B.Sc. Nursing and only $20 \%(n=6)$ of nurses had done B.Sc. Nursing, whereas in the private hospital, $86.7 \%(n=26)$ nurses had done DGNM, followed by both $6.7 \%(n=2)$ of nurses were educated up to Post B.Sc. Nursing and B. Sc. Nursing.

In the government hospital, only $20 \%(n=6)$ nurses had attended in-service education regarding neonatal skin care in the past 6 months whereas in the private hospital, only $6.7 \%(n=2)$ nurses had attended in-service education regarding neonatal skin care in the past 6 months. 
Table 1.Competency among Nurses in Neonatal Skin Care in the Government and Private Hospital

\begin{tabular}{|c|c|c|c|c|c|c|c|c|}
\hline & & & & & & & & $\mathrm{n}_{1}=30, \mathrm{n}_{2}=3$ \\
\hline S.No. & Competency & Group & Mean & Mean Differ & SD & df & 't' Value & 'p' Value \\
\hline \multirow[t]{2}{*}{1} & \multirow{2}{*}{$\begin{array}{c}\text { Neonatal skin } \\
\text { assessment }\end{array}$} & Government & 10.67 & \multirow[b]{2}{*}{1.8} & 1.061 & \multirow{2}{*}{58} & \multirow{2}{*}{6.006} & \multirow{2}{*}{$0.00001^{*}$} \\
\hline & & Private hospital & 8.87 & & 1.252 & & & \\
\hline \multirow[t]{3}{*}{2} & \multirow{3}{*}{$\begin{array}{c}\text { Neonatal skin } \\
\text { care }\end{array}$} & Government & 6.63 & \multirow[b]{3}{*}{1.66} & 0.669 & \multirow{3}{*}{58} & \multirow{3}{*}{7.982} & \multirow{3}{*}{$0.00001^{*}$} \\
\hline & & hospital & & & & & & \\
\hline & & Private hospital & 4.97 & & 0.928 & & & \\
\hline 3 & Eye care & Government & 19.13 & \multirow[b]{3}{*}{6.26} & 1.432 & \multirow{3}{*}{58} & \multirow{3}{*}{11.811} & \multirow{3}{*}{$0.00001^{*}$} \\
\hline & & hospital & & & & & & \\
\hline & & Private hospital & 12.87 & & 2.529 & & & \\
\hline 4 & Umbilical cord & Government & 17.97 & \multirow[b]{3}{*}{3.64} & 0.765 & \multirow{3}{*}{58} & \multirow{3}{*}{7.547} & \multirow{3}{*}{$0.00001^{*}$} \\
\hline & care & hospital & & & & & & \\
\hline & & Private hospital & 14.33 & & 2.523 & & & \\
\hline 5 & Diaper care & Government & 15.03 & \multirow[b]{3}{*}{2.24} & 0.850 & \multirow{3}{*}{58} & \multirow{3}{*}{5.659} & \multirow{3}{*}{$0.00001^{*}$} \\
\hline & & hospital & & & & & & \\
\hline & & Private hospital & 12.79 & & 1.989 & & & \\
\hline
\end{tabular}

Table 2.Comparison of Competency among Nurses in Giving Neonatal Skin Care Procedures in Government and Private Hospital

\begin{tabular}{|c|c|c|c|c|c|c|c|c|}
\hline S. No. & Group & $\mathbf{N}$ & Mean & Mean Difference & SD & df & 't' Value & 'P' Value \\
\hline 1 & $\begin{array}{l}\text { Competency of nurses working in } \\
\text { government hospital }\end{array}$ & 30 & 69.27 & \multirow[t]{2}{*}{15.54} & 2.728 & \multirow[t]{2}{*}{58} & \multirow[t]{2}{*}{10.210} & \multirow[t]{2}{*}{$0.00001^{*}$} \\
\hline 2 & $\begin{array}{l}\text { Competency of nurses working in } \\
\text { private hospital }\end{array}$ & 30 & 53.73 & & 7.874 & & & \\
\hline
\end{tabular}

\section{Discussion}

The study aimed to assess the competency among nurses in giving neonatal skin care in the selected government and a private hospital in Delhi and to compare the competency among nurses in giving neonatal skin care in a selected government and a private hospital in Delhi. The objectives also included dissemination of TNAI guidelines 2017 on the neonatal skin care to the nurses. The guidelines were disseminated after data collection and no post-intervention was given after the dissemination.

The final result of the study reveals that the competency among the nurses working in the government hospital is higher than among the nurses working in the private hospital. This result is in line with a study conducted by Waiswa et al. in eastern Uganda to assess the differences in essential newborn care at birth between private and public health facilities. 395 samples were taken for this study and it was concluded that practice score of the government hospital was higher than the practice score of the private hospital. These findings are supported by a study done by
Waiswa et al. which revealed that babies born in public health facilities were more likely to receive more individual newborn care practices compared to their private health facility counterparts. Whereas $42.8 \%$ of babies born in public facilities received at least eight essential newborn care practices, only $27.5 \%$ in private facilities received the same eight essential newborn care practices. Nearly all $(98 \%)$ babies born in public health facilities received at least three practices, compared to $95 \%$ amongst those in private health facilities. ${ }^{5}$

\section{Conclusion}

The researcher has conducted this study to find out the comparison between the level of competencies among nurses in a government and a private hospital regarding neonatal skin care and the result reveals that the nurses who were in government hospital had higher competency regarding neonatal skin care procedures as compared to nurses who were in the private hospital.

Conflict of Interest: None 


\section{References}

1. Larson A, Dinolos J. Cutaneous bacterial infection in the newborn. Current Opinion in Paediatrics 2005; 17: 480.

2. Fox C, Nelson D, Wareham J. The timing of skin acidification in very low birth weight infants 1998; 18(4): 272-75.

3. Ness MJ, Davis DM, Carey WA. Neonatal skin care: $A$ concise review 2013 Jan; 52(1): 14-22.
4. Lund, Carolyn. Issue in newborn skin care. 2016 Oct;16: S1-S2.

5. Waiswa P, Pariyo G, Kallander $K$ et al. Effect of the Uganda newborn study on care-seeking and care practices: A cluster-randomised controlled trial 2015; 8: 10.3402 .

Date of Submission: 2018-05-22 Date of Acceptance: 2018-06-23 